\title{
SMARTPHONE-BASED SENSING: LIFESTYLE AND MOBILITY DATA INTERPRETATION BY SMART CITIES
}

\author{
LADISLAVA FIALKA SOBKOVÁ, ŠIMON JIRÁČEK \& MICHAL ČERTICKÝ \\ Czech Technical University, Czech Republic
}

\begin{abstract}
The increasing demand for data and smart solutions is one of the fastest growing sectors of human activity. In recent decades smartphones and mobile phones have become a significant and stable source of data. Architects and urban planners have used them in various cases to identify urban patterns. This paper focuses on data gathered by fitness tracker applications which collect information about the movement of their users. The applications record the trajectory of the movement and detect the mode of transport. They require some basic information about the user (age, weight, height and sex) to calculate their caloric consumption. The data from activity tracking smartphone applications create a data lake that can be transformed into a new data source for the designing of healthier and more liveable cities. Combining the data layers and analysing them further could reveal properties and qualities of life in a given location that would not be apparent without processing these data. By analysing the data, we can observe the current state as well as tendencies in human behaviour over longer periods of time. Through the observation and comparison of physical activity in different urban contexts (topography, size of settlement, density of population, density of infrastructure, quality of public spaces, location, etc.), we can develop new alternatives and better knowledge of the influence the above-mentioned factors have on the life in cities. This paper describes data layer combinations that bring novel insights into the connection of physical activity and urban contexts by using data mining technology based on smartphone applications. The theoretical framework can be subsequently applied to various data sets with certain properties.
\end{abstract}

Keywords: city sensing, data mining, smartphone, physical activity, fitness tracker, strategy, smart city, interpretation.

\section{INTRODUCTION}

The cities of today are continuously producing large amounts of data [1]. The data can be gained automatically by many different sensors [2], which are a part of the public space and its facilities, or the data can be produced by the users of the city - its inhabitants [3]. $63 \%$ of the population in the Czech Republic have a smartphone. Among young people in the age of 16-24 years, the share is $95 \%$ [4]. An average user of a smartphone has 80 apps installed on their phone and uses almost 40 of them each month [5].

The movement of people is like the blood circulating in the veins of a city - a better knowledge of their mobility is crucial for various branches of human activities. The habits of the inhabitants of a city and their connection with various influence factors could be revealed also by analysing data gained by smartphone applications. This paper focuses on the data collected and transmitted by lifestyle-monitoring or activity tracking applications.

Currently there is also an increasing number of applications tracking the users' mobility to help in the fight against the Covid-19 pandemic [6], [7], which are based on the users' voluntary consent to share their geolocation data in time. In the Czech Republic, $14.9 \%$ of the population share their personal time and geo-tagged data in the Mapy.cz application [8], [9]. This application is a part of the governmental project Smart Quarantine aimed to assess risky contacts with persons who have tested positively for Covid-19 [9], [10]. 


\section{METHODOLOGY}

The goal of the research is the description of different methodologies to use smartphone data. The research comprised three main phases:

- Specification of data sources and data categories;

- A literature review;

- Defining a novel use of the data obtained from fitness applications.

First, we identified the classes of data that users of these fitness and lifestyle applications provide through their smartphones. We used a data set from applications that provide information about the user's caloric expenditure as a basis. Subsequently, we identified alternative types of applications that collect the same data classes but provide users with a different benefit.

A research of English-language scientific literature was performed primarily by searching Web of Science, Google Scholar and ResearchGate. The search was limited to items published between 1975 and June 2020 and the keywords included "smartphone", "fitness", "lifestyle", "physical activity", "walkability", "mobility", "biking", "urban", "city". We searched the results for articles related to the topic of this study. We selected studies that could be repeated or conducted by using smartphone application data.

The bibliographies of the selected articles were examined for further relevant articles. Links found on websites where these articles were published were also searched for pertinent information.

Based on the literature review, thematically specific categories of data use in the urban sphere were created. Furthermore, the necessary input data for these individual categories were determined.

Data from fitness applications can be used also in other ways that have not yet been described in literature or implemented by using conventionally obtained data. A description of these innovative approaches to the data set, their importance and benefits is included in Section 4.

\section{STATE OF THE ART}

\subsection{Data sources}

In applications that monitor the user's movement patterns, the user usually has to select the activity manually, or the application uses the acceleration data obtained from a gyroscope and an accelerometer [11]. The application analyses the data gained from these sensors and identifies the type and mode of movement based on the shape of the acceleration curve. Applications with access to the location of the device can obtain more precise data by comparing the movement trajectory in time with the trajectories of public transport in space and time [12]. Geolocation data may be obtained through GPS or network-based location sensing technology, which drains the battery less [13].

Data gathered by the applications can be stored in databases. In each country, the collection, storage and use of such data is regulated by the respective national legislation [14], [15].

\subsubsection{Fitness trackers}

Fitness tracking applications and pedometers (Google Fit, Endomondo, Moves, MiFit, etc.) are primarily used to obtain information about the user's daily movement pattern, sports performance and calorie consumption. To find out their calorie consumption, the user has to 
enter certain basic factors influencing their metabolism, i.e. their age, weight, height and sex (see Fig. 1). The application software uses the above-mentioned methods to identify the type of movement (see Fig. 2). It can use geolocation data as additional information. Fitness tracking applications installed on smartphones can be often linked with further wearable devices which provide additional, more precise information on the user's activity, e.g. fitness bands, smartwatches, smart clothing with wearable technologies, etc. [16].

\subsubsection{Mobility monitoring applications}

Mobility monitoring applications provide the user with feedback on their transport behaviour, i.e. the choice of route and mode of transport. The $\mathrm{CO} 2 \mathrm{GO}$ application, developed by MIT, suggested alternative routes and modes of transport in real time to reduce the user's carbon footprint while keeping a similar travel time [17]. UN Carbon Footprint Calculator, Carbon footprint and $\mathrm{CO}_{2}$ tracker and other applications are based on a similar principle.

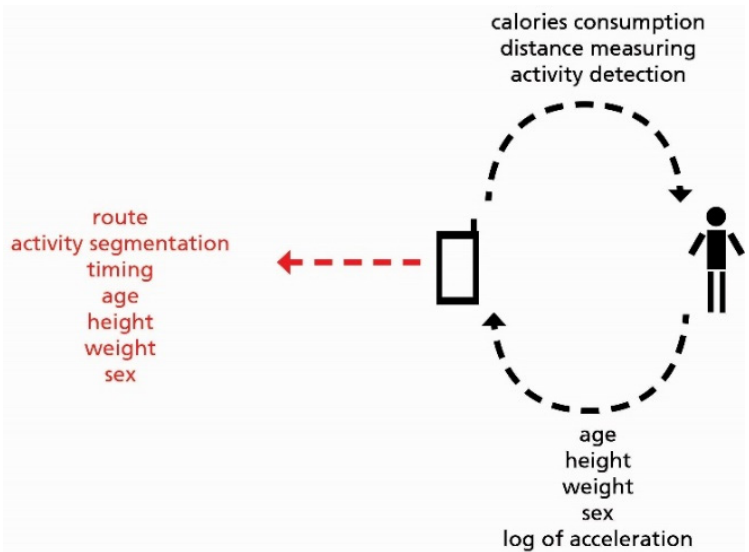

Figure 1: Scheme of the data-flow.

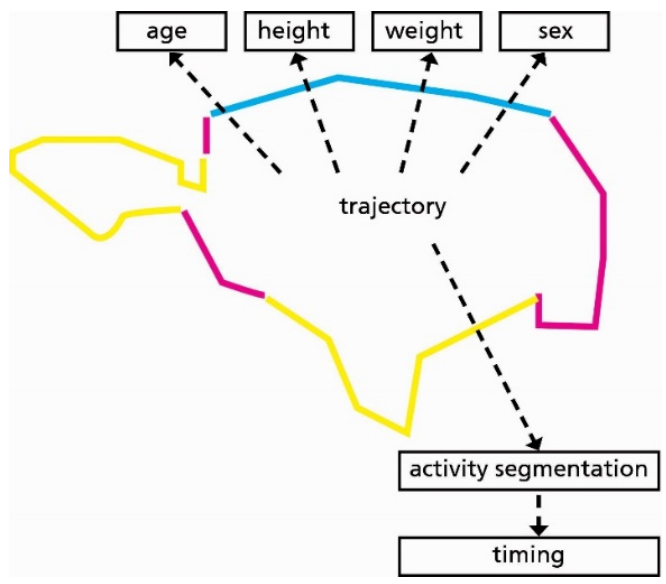

Figure 2: Scheme of the segmentation of trajectory. 


\subsubsection{Healthcare applications}

Tracking and activity monitoring applications are also often used in healthcare, in particular by patients with cardiovascular diseases. In combination with up-to-date information from the patient's wearable monitoring devices, such applications can be used to develop tailormade motivation programmes for the patient. As the devices monitor the user's pulse and location as well, they can be crucial in providing the patient with quick help in case of health problems [18]. Movement tracking can also increase the safety of patients with neurological diseases (such as Alzheimer's), especially when they become disoriented or get lost [19].

Smartphone apps are also used for the purposes of epidemiological measures, such as the above-mentioned Smart Quarantine project in the Czech Republic [10].

\subsection{Data utilization}

\subsubsection{Tracking tool for urban research}

Mobile applications are a new research tool. They can collect data more efficiently and with more precise temporal information than traditional questionnaires. Using a smartphone is a regular daily activity and thus does not disturb the users (respondents) in any way [20]. Smartphones collect data in a passive manner and create low-burden protocols over a long period of time [21]. This advantage has been used for example in a study of urban vitality conditions conducted in Barcelona [22], which utilized the Moves ${ }^{\mathscr{O}}$ application to aggregate data on the mode and trajectory of the participants' movement [23]. The data obtained were used to compare the activity of pedestrians in pedestrian activity spaces and in residential buffers.

The INTERACT study monitored the physical activity of its participants in four Canadian cities; the data were aggregated using the Ethica $^{\odot}$ application which was developed specifically for the purposes of scientific research studies [24]. When designing a study, the researchers can select which activities and sensor-based data will be monitored. The participants can join the study by downloading the application and signing in through a registration link. The data from the participants' application are available for analysis in real time [25]. The INTERACT study aims at collecting a database of $100 \mathrm{~TB}$ data which will be made available for analysis also to other research teams [24].

\subsubsection{Evaluation of urban interventions}

The World Health Organization/Europe has released the Health Economic Assessment Tool (HEAT) which is designed to assess the economic impacts of urban interventions that cause changes in the transport behaviour of people [26]. The HEAT method calculates the economic value of the health effects arising from cycling and walking. It compares the participants' condition before and after the project. Data from smartphone-based fitness trackers and mobility monitoring applications [20] can be used for assessment, if they are obtained from the respective area in sufficient density. However, the input data will have to be adjusted before use to make up for the difference between the actual numbers of persons cycling/walking through the respective area according to traffic surveys and the number of the application users passing through the area.

\subsubsection{Property value and walkability correlation}

Based on an analysis of public space and the knowledge of how it is used, locations with economic potential can be identified. A subsequent change in the arrangement of the public space and facilitation of the way it is used can have a demonstrable effect on the value of 
properties in the given area. This qualitative aspect is then demonstrated by a different price in comparison with properties in other similar locations with similar conditions.

In 2019, TC Group examined the relation between rent rates and the intensity of walking movement in a number of streets in European cities [27]. Calculated on the basis of the respective rents, the passing of one pedestrian in front of a commercial unit in the Gran Via street in Madrid cost 3.93 Eurocents, the passing of one pedestrian in the Serrano street cost 10.62 Eurocents, while the average rent was similar in both streets. In the latter case, thus, a shop owner has to pay twice as much for one potential customer to pass along their shop.

A careful choice of the location based on information about the movement in the given street, neighbourhood or whole town can thus optimize the operation costs of a commercial unit. The permeability of traffic in a street can by itself influence the rent rates of premises on the ground floor by $10 \%$ to $30 \%$ [28]. However, the perspective could be turned around and the available data could be used to point out the potential of individual areas to increase the value of these areas through adequate interventions in their arrangement.

The permeability of public space, i.e. the fluency with which the area can be passed through, is another factor contributing to a difference in the value of a property [29]. Local improvements can be achieved by increasing the number of possible crossings along the most natural route and by adjusting the number and setting of traffic lights to increase the inclusive fluency for pedestrians to the disadvantage of cars. Increasing the walking permeability by $10 \%$ can increase the value of a property by $1-9 \%$ [30]. Already the definition of a street network is a crucial influence on the economic aspect in question [31].

\section{SMART CITY: USING DATA FROM MOBILE APPLICATIONS}

Data from smartphone applications can be used as a data source for long-term monitoring of physical activity (PA). In relation to municipal and urban spaces, PA can be monitored and analysed in various contexts.

Every application aggregates and produces only such data that serve the purpose of the given application. Table 1 shows which data are usually collected by the applications listed in 2.1. The overview of categories and groups of collected data provided in Table 1 is arranged to facilitate their interpretation and thus to help understand and improve the living conditions in built-up areas. The proposed analyses aim at expanding our knowledge of urban environments and enabling studies that will serve as a solid basis for the designs created by urban planners and for the decision making of municipalities.

\subsection{Walkable distance research}

Walkable distance is defined as a referential value or normative value of the greatest distance people are willing to walk from a residential house to facilities providing essential services or to public transport stations [32]. This value should be adjusted in time, as it is influenced by the readiness of the residents to reach their destination without using any other mode of transport than walking. Long-term tendencies can be observed in the PA data obtained from smartphone applications whose users replace the role of respondents in traditional questionnaires.

In terms of walkable distance, various factors can have an influence on the user's decisions about daily mobility. Potential influence factors include:

- Total commuting time;

- Carpooling possibilities;

- $\quad$ Time loss in case of alternative means of transport (bike, walking, public transport); 
Table 1: Table of database and data employment.

\begin{tabular}{|c|c|c|c|c|c|c|c|}
\hline Usage of the data & نัّ & $\underset{0}{\infty}$ & 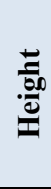 & $\sum_{i}^{\frac{E}{20}}$ & نิ & $\sum_{\bar{g}}^{\frac{0}{z}}$ & $\begin{array}{c}\text { Additional } \\
\text { information }\end{array}$ \\
\hline Walking distance and commuting & $\mathbf{x}$ & $\mathbf{x}$ & $\mathbf{x}$ & $\mathbf{x}$ & $\mathbf{x}$ & $\mathbf{x}$ & \\
\hline Total commuting time & $\mathrm{x}$ & $\mathrm{x}$ & & & $\mathrm{x}$ & $\mathrm{x}$ & \\
\hline Possibility of carpooling & $\mathrm{x}$ & $\mathrm{x}$ & & & $\mathrm{x}$ & $\mathrm{x}$ & \\
\hline Time loss & $\mathrm{x}$ & $\mathrm{x}$ & & & $\mathrm{x}$ & $\mathrm{x}$ & $\begin{array}{c}\text { Public transport } \\
\text { timetable }\end{array}$ \\
\hline Cost reduction & $\mathrm{x}$ & $\mathrm{x}$ & & & $\mathrm{x}$ & $\mathrm{x}$ & $\begin{array}{c}\text { Cost of fuel }+ \text { public } \\
\text { transport }\end{array}$ \\
\hline Advantage in the field of PA & $\mathrm{x}$ & $\mathrm{x}$ & & & $\mathrm{x}$ & $\mathrm{x}$ & \\
\hline $\begin{array}{l}\text { A comparison of the spatial } \\
\text { dependence of BMI } \\
\end{array}$ & $\mathbf{x}$ & $\mathbf{x}$ & $\mathbf{x}$ & $\mathbf{x}$ & $\mathbf{x}$ & $\mathbf{x}$ & \\
\hline In different age groups & & $\mathrm{x}$ & $\mathrm{x}$ & $\mathrm{x}$ & $\mathrm{x}$ & $\mathrm{x}$ & \\
\hline Influence of gender & $\mathrm{x}$ & & $\mathrm{x}$ & $\mathrm{x}$ & $\mathrm{x}$ & $\mathrm{x}$ & \\
\hline Overview in time & $\mathrm{x}$ & $\mathrm{x}$ & $\mathrm{x}$ & $\mathrm{x}$ & $\mathrm{x}$ & $\mathrm{x}$ & Timeframe \\
\hline Physical activity (PA) research & $\mathbf{x}$ & $\mathbf{x}$ & $\mathbf{x}$ & $\mathbf{x}$ & $\overline{\mathbf{x}}$ & $\mathbf{x}$ & \\
\hline Dependency PA/sex and age & $\mathrm{x}$ & $\mathrm{x}$ & & & $\mathrm{x}$ & $\mathrm{x}$ & \\
\hline Dependency PA/sex and BMI & $\mathrm{x}$ & & $\mathrm{x}$ & $\mathrm{x}$ & $\mathrm{x}$ & $\mathrm{x}$ & \\
\hline Dependency PA/age and BMI & & $\mathrm{x}$ & $\mathrm{x}$ & $\mathrm{x}$ & $\mathrm{x}$ & $\mathrm{x}$ & \\
\hline PA: overview in time & $\mathrm{x}$ & $\mathrm{x}$ & $\mathrm{x}$ & $\mathrm{x}$ & $\mathrm{x}$ & $\mathrm{x}$ & Timeframe \\
\hline $\begin{array}{l}\text { Research of influence of topography at } \\
\text { PA }\end{array}$ & $\mathbf{x}$ & $\mathbf{x}$ & $\mathbf{x}$ & $\mathbf{x}$ & $\mathbf{x}$ & $\mathbf{x}$ & \\
\hline BMI in different topographies & & & $\mathrm{x}$ & $\mathrm{x}$ & $\mathrm{x}$ & $\mathrm{x}$ & \\
\hline Biking in different topographies & $\mathrm{x}$ & $\mathrm{x}$ & & & $\mathrm{x}$ & $\mathrm{x}$ & Plan of bicycle paths \\
\hline Walking in different topographies & $\mathrm{x}$ & $\mathrm{x}$ & & & $\mathrm{x}$ & $\mathrm{x}$ & $\begin{array}{l}\text { Plan of pedestrian } \\
\text { paths }\end{array}$ \\
\hline $\begin{array}{l}\text { Research influence of character of } \\
\text { settlement at PA }\end{array}$ & $\mathbf{x}$ & $\mathbf{x}$ & $\mathbf{x}$ & $\mathbf{x}$ & $\mathbf{x}$ & $\mathbf{x}$ & \\
\hline $\begin{array}{l}\text { Influence of density/quality of } \\
\text { infrastructure }\end{array}$ & $\mathrm{x}$ & $\mathrm{x}$ & $\mathrm{x}$ & $\mathrm{x}$ & $\mathrm{x}$ & $\mathrm{x}$ & Plan of infrastructure \\
\hline Influence of green infrastructure & $\mathrm{x}$ & $\mathrm{x}$ & $\mathrm{x}$ & $\mathrm{x}$ & $\mathrm{x}$ & $\mathrm{x}$ & $\begin{array}{l}\text { Plan of green } \\
\text { infrastructure }\end{array}$ \\
\hline $\begin{array}{l}\text { Influence of public transport } \\
\text { infrastructure }\end{array}$ & $\mathrm{x}$ & $\mathrm{x}$ & $\mathrm{x}$ & $\mathrm{x}$ & $\mathrm{x}$ & $\mathrm{x}$ & $\begin{array}{l}\text { Plan of public } \\
\text { transport }\end{array}$ \\
\hline Influence of security landscaping & $\mathrm{x}$ & $\mathrm{x}$ & $\mathrm{x}$ & $\mathrm{x}$ & $\mathrm{x}$ & $\mathrm{x}$ & $\begin{array}{c}\text { Plan + report of } \\
\text { measures }\end{array}$ \\
\hline $\begin{array}{l}\text { Research of walkability of public space } \\
\text { at PA }\end{array}$ & $\mathbf{x}$ & $\mathbf{x}$ & & & $\mathbf{x}$ & $\mathbf{x}$ & $\begin{array}{l}\text { Using Walkability } \\
\text { Index influence } \\
\text { factors }\end{array}$ \\
\hline Economic assessment & $\mathbf{x}$ & $\mathbf{x}$ & & & $\mathbf{x}$ & $\mathbf{x}$ & $\begin{array}{l}\text { Overcount of the } \\
\text { input data }\end{array}$ \\
\hline Economic assesment for cycling & $\mathrm{x}$ & $\mathrm{x}$ & & & $\mathrm{x}$ & $\mathrm{x}$ & Using HEAT \\
\hline Economic assesment for walking & $\mathrm{x}$ & $\mathrm{x}$ & & & $\mathrm{x}$ & $\mathrm{x}$ & Using HEAT \\
\hline $\begin{array}{l}\text { Economic assesment for carbon } \\
\text { emissions production }\end{array}$ & $\mathrm{x}$ & $\mathrm{x}$ & & & $\mathrm{x}$ & $\mathrm{x}$ & Level of air pollution \\
\hline $\begin{array}{l}\text { Property value and walkability } \\
\text { correlation }\end{array}$ & & & & & $\mathrm{x}$ & $\mathrm{x}$ & $\begin{array}{l}\text { Cost of property } \\
\text { value }\end{array}$ \\
\hline
\end{tabular}


- Cost reduction in case of alternative means of transport;

- Increased physical activity required for alternative modes of transport.

4.2 A comparison of the spatial dependence of body mass index (BMI)

BMI is a measure for indicating nutritional status in adults [33]. It is defined as:

$$
\mathrm{BMI}=\frac{\text { weight }[\mathrm{kg}]}{\text { height }^{2}[\mathrm{~m}]} \text {. }
$$

Various studies have proven a connection between neighbourhood supportiveness for physical activity and BMI [34], [35]. There are also case studies that have examined the spatial dependence of BMI in certain localities [36]. We propose to use data from smartphone applications as source data for examining the influence of urban factors on BMI. Previous research has shown multiple interrelationships when examining BMI spatial dependence (social, individual and environmental - which are necessary to distinguish). This paper focuses on environmental factors because they can be influenced by changes in the development of public space, land use and transportation [37]. However, environmental factors can be also linked to gender or age groups which evince a higher rate of BMI relation to locality.

\subsection{Physical activity research}

The readiness to rely on one's own physical activity (such as cycling or walking) as a means of transport is essential in any city. Cycling has become an integral part of the identity of cities such as Copenhagen and Berlin. The acceptance of physical activity is not permanent, it changes in time: the motion patterns of inhabitants will differ in winter and in summer as well as under exceptional conditions (such as the Covid-19 epidemic or restricted operation of public transport). Regular physical activity does not only affect the individual by contributing to the prevention of diseases of affluence and by supporting mental well-being [38], [39], it also affects the liveliness and the economy of cities. It is therefore in the interest of municipal administrations to regard the physical activity of the users of public spaces as a relevant issue and to use is as a basis when introducing new measures (pedestrianisation, creating a barrier-free environment and installing street furniture in public spaces, promoting the construction of bike paths).

Databases containing the data categories indicated in Table 1 can provide data to examine the influence of sex, age [40] and BMI on ordinary daily physical activity of the population.

\subsection{Research on the influence of topography on PA}

In connection with the introduction of measures aimed at supporting cycling as a means of transport in Prague, one dissenting and unsubstantiated argument was mentioned in many discussions: Prague's topography (moderately undulating terrain) is not favourable for the development of cycling, the investment in this direction is therefore pointless [41]. However, with the advent of electromobility, this argument is losing ground. Moreover, there have been no studies in culturally comparable cities which would provide real data from different topographies and confirm or refute the aforementioned statement.

Data from smartphone applications listed in 2.1 seem to be a suitable basis to examine the hypothesis that hilly areas have a lower share of bicycle traffic and to establish a relation between cycling and local topography. When analysing such data (same as when analysing the influence of topography on walking), it is necessary to consider the fact that topography 
is one of the influence factors. Further major influence factors are the density, quality and safety of bike paths in the given area [42], [43].

When assessing the influence of topography on walking and BMI, it is necessary to account for the social and individual aspects mentioned in 3.2. Walking is also linked to other environmental influence factors that are defined in many studies as the area's walkability index [44], [45].

\subsection{Research on the influence of the size and character of a settlement on PA}

Data from the mobile applications listed in 2.1 can be used to measure the influence of lifestyle on the physical activity in various types of settlements and to verify the results in time. An interesting way of using such data could be to compare the physical activity in times of the Covid-19 pandemic in settlements that are different in size and whose population is currently affected by the virus to a different extent.

The individual settlements can be sorted by the type and character of the buildings (historical vs. industrial buildings), their density, number of inhabitants as well as the quality and density of the services and facilities available, which also includes accessibility and elements of green infrastructure.

\subsection{Research on the influence of walkability of public space on PA}

The walkability index [44], [45] can be combined with the data from databases including the categories listed in Table 1 to assess a given locality and to examine the relation between the walkability index and the physical activity in the area.

As the data are collected over a long period of time, it is possible to observe and measure the relation between the walkability index and the mobility behaviour of the users of public spaces in the given locality before and after the locality has been adjusted. Observing the relation between the individual variables can be used to update or localise the formulas for the calculation of the walkability index.

\subsection{Economic assessment}

The HEAT methodology, developed by the World Health Organization/Europe, uses the input data to calculate the economic impact of the health effects caused by a change in the way public and other spaces are used [26]. Where data from traffic surveys are not available or accessible, data from the applications mentioned in 2.1 can be used when recalculated in an appropriate manner to determine an approximate impact of past investments.

The pedestrianisation of streets does not bring benefits only in the field of public health. It is also proven that pedestrianisation of public spaces in city centres also has a positive economic effect [46]. After an examination of the relation between the rent rates and the intensity of the use of public spaces in the given locality, it will be possible to assess the effects of the adjustment of the public space on the income from properties adjacent to the respective public spaces in the given locality. Data from smartphone applications listed in 2.1 can be used to calculate the economic effects of investments in public space from the point of view of the owners of adjacent properties. 


\section{DISCUSSION}

\subsection{Data properties}

Unlike data from mobile network providers (which, however, lack the precision based on GPS), data obtained from smartphone applications will probably not cover the whole population. Their density, i.e. the number of users in population, depends on how widely spread the given application is among smartphone users. The number of users also changes in time and can be influenced by marketing measures and specific features of the application. Moreover, GPS coverage is not fully guaranteed, as it is weaker for example inside of buildings. Battery draining when GPS is on remains a complication [13], which is why a part of the users turns off this functionality manually and by doing so decreases the precision of movement tracking.

\subsection{Data accuracy}

Individual applications demonstrate different levels of accuracy. For research purposes, it is ideal to obtain raw data, which are more flexible for use and analysis. When it is not possible to obtain raw data, inaccurate data should be marked or deleted from the data set completely [20].

Smartphone application data represent only a particular segment of the population. Fitness and activity tracking applications are used only by persons who take an active interest in their health and who therefore wish to monitor their daily physical activity. Users of the applications listed in 2.1.2 are concerned about the ecological impact of their own mobility behaviour on the environment. Applications mentioned under 2.1.3 are used by individuals with specific health problems.

Such specific qualities of the users have to be taken into consideration at all times. Based on further research, the data can be calibrated for a specific sample of the population.

\subsection{Data utilization}

The data utilization has to be adjusted according to how many users have installed the given application. Some applications will probably not provide an adequate sample of the population for all types of research projects (e.g. due to an insufficient number of users in a given locality) [47].

The data can be approached as follows:

- Application users are viewed as passive respondents of a survey.

- The data can be calibrated by expanding them on the total number of inhabitants, e.g. to use them as a replacement for a traffic survey (which, however, can be done only if the density of users in the given locality is high enough).

- Source data for further modelling - the research data set will be created as a result of a model (traffic modelling, agent-based models, activity-based models). In this case, the data can replace traffic survey logs.

\subsection{Access to data}

Mobile application databases are not a publicly available source of data. Access to such data can be granted by individual application users (only their own data processed by the application are provided) or by the publisher and operator of the given application (data processed by the application as well as raw data are provided). 
Access to databases containing private data of the users - where geolocation and health data definitely have to be regarded as private data - is regulated in each country by the respective national legislation. From an ethical point of view, the application users should give their consent to the purpose for which the data are provided and this purpose should be precisely defined by the publisher of the application.

\section{CONCLUSION}

The paper brings an overview of how data obtained from smartphone fitness applications can be used for urban purposes and shows how the described research methods can be easily repeated or revised in different places, conditions or over a defined period of time. Fitness and activity tracking applications installed on smartphones collect data about the users' mobility and the modes of transport they choose. At the same time, they aggregate information on the users' weight, height, age and gender, which is necessary for the calculation of their calorie consumption. Such data allow us to find answers to questions regarding mobility habits of a large sample of the population without the need to actively address respondents.

Datasets obtained from these applications can be used to conduct research on commuting, walkable distances and the factors influencing them. Moreover, they can be used to compare spatial dependence and BMI and to examine regular daily physical activities in individual groups of the population. They can also serve as a basis for researching the influence of topography and of the settlement characteristics on the daily activities of the inhabitants.

In case of sufficient density of the data, they can be calibrated and used to research the walkability of urban spaces as well as the interrelation of the individual variables of walkability indexes and the physical activity in specific localities. Such adjusted data can also be utilized to assess the economic impacts of regular daily physical activity in urban environments. Research can be conducted also on the basis of data from mobility models. Such models integrate data from mobile applications, which thereby replace traffic survey logs.

\section{ACKNOWLEDGEMENT}

This paper was created with the support from grant number SGS20/077/OHK1/1T/15.

\section{REFERENCES}

[1] Batty, M., Big data, smart cities and city planning. Dialogues in Human Geography, 3(3), pp. 274-279, 2013.

[2] Batty, M., The New Science of Cities, The MIT Press: Cambridge, MA and London, pp. 15-18, 2017.

[3] Goodchild, M.F., Citizens as sensors: the world of volunteered geography. GeoJournal, pp. 211-221, 2007.

[4] Czech Statistical Office (CZSO), Individuals using mobile phone in the Czech Republic, 2018. www.czso.cz/documents/10180/61508128/0620041823.pdf/ 62afeb86-2c8f-4b8f-9dd2-cd5873ce02a9?version=1.2. Accessed on: 18 Jul. 2019.

[5] App Annie, Monthly average number of apps used and installed: Smartphone users in selected markets, 2017. www.appannie.com/en/insights/market-data/apps-used-2017/. Accessed on: 18 Jul. 2019.

[6] Iyengar, K., Upadhyaya, G.K., Vaishya, R. \& Jain, V., COVID-19 and applications of smartphone technology in the current pandemic. Diabetes and Metabolic Syndrome Clinical Research and Reviews, 14, pp. 733-737. 
[7] Cohen, I.G., Gostin, L.O. \& Weitzner, D.J., Digital smartphone tracking for COVID19. JAMA, 323(23), pp. 2371-2372.

[8] Czech Statistical Office (CZSO), Population at March 2020. www.czso.cz/csu/czso/ population. Accessed on: 26 Jul. 2020.

[9] Mapy.cz, Let's stop the spread of coronavirus together. www.seznam.cz/zastav-covid/. Accessed on: 26 Jul. 2020.

[10] Ministry of Health of Czech Republic, Smart quarantine. https://koronavirus.mzcr.cz/ chytra-karantena/. Accessed on: 26 Jul. 2020.

[11] Bort-Roig, J., Gilson, N.D., Puig-Ribera, A., Contreras, R.S. \& Trost, S.G., Measuring and influencing physical activity with smartphone technology: A systematic review. Sports Medicine, pp. 671-686, 2014.

[12] Shin, D., Urban sensing by crowdsourcing: Analysing urban trip behaviour in Zurich. Int. J. Urban Regional, 40, pp. 1044-1060, 2016.

[13] Shin, D., Aliaga, D., Tunçer, B., Arisona, S.M., Kim, S., Zünd, D. \& Schmitt, G., Urban sensing: Using smartphones for transportation mode classification. Computers, Environment and Urban Systems, 2014.

[14] Kunz, T., Lange, B. \& Selzer, A., Datenschutz und Datensicherheit in digital public health. Bundesgesundheitsblatt - Gesundheitsforschung - Gesundheitsschutz, 63(2), pp. 206-214, 2020.

[15] Polykalas, S.E. \& Prezerakos, G.N., When the mobile app is free, the product is your personal data. Digital Policy Regulation and Governance, 21(2), pp. 89-101, 2019.

[16] Higgins, J.P., Smartphone applications for patients health and fitness. The American Journal of Medicine, 129(1), 2016.

[17] $\mathrm{CO} 2 \mathrm{GO}$, Calculating your carbon footprint automatically and in real-time while on the move. http://senseable.mit.edu/co2go/. Accessed on: 18 Jul. 2020.

[18] Dobrican, R.A. \& Zampunieris, D.A., Proactive solution, using wearable and mobile applications, for closing the gap between the rehabilitation team and cardiac patients. 2016 IEEE International Conference On Healthcare Informatics (ICHI), pp. 146-155, 2016.

[19] Armstrong, N., Nugent, C., Moore, G. \& Finlay, D., Using smartphones to address the needs of persons with Alzheimer's disease. Annals of Telecommunications - Annales des Télécommunications, 65, pp. 485-495, 2010.

[20] Clarke, A. \& Steele, R., How personal fitness data can be re-used by smart cities. 2011 Seventh International Conference on Intelligent Sensors, Sensor Networks and Information Processing, pp. 395-400, 2011.

[21] Perchoux, C., Chaix, B. \& Kestens, Y., Activity spaces in place and health research: Novel exposure measures, data collection tools, and designs. Health and Place, 58, 2019.

[22] Delclòs-Alió, X., Gutiérrez, A. \& Miralles-Guasch, C,. The urban vitality conditions of Jane Jacobs in Barcelona: Residential and smartphone-based tracking measurements of the built environment in a Mediterranean metropolis. Cities, 86, pp. 220-228, 2019.

[23] Evenson, K.R. \& Furberg, R.D., Moves app: A digital diary to track physical activity and location. British Journal of Sports Medicine, 51, pp. 1169-1170, 2017.

[24] Kestens, Y. et al., INTERACT: A comprehensive approach to assess urban form interventions through natural experiments. BMC Public Health, 2019.

[25] Product - Ethica, https://ethicadata.com/product. Accessed on: 20 Jul. 2020.

[26] Health Economic Assessment Tool (HEAT) for walking and cycling by WHO/Europe. www.heatwalkingcycling.org/\#homepage. Accessed on: 20 Jul. 2020. 
[27] TC Group Solutions, Footfall and CPC report on European high streets 2019. www.tcgroupsolutions.com/en/reports/. Accessed on: $20 \mathrm{Jul} .2020$.

[28] D'Acci, L., Quality of urban area, distance from city centre, and housing value: Case study on real estate values in Turin. Cities, 91, pp. 71-92, 2019.

[29] Gilderbloom, J.I., Riggs, W.W. \& Meares, W.L., Does walkability matter? An examination of walkability's impact on housing values, foreclosures and crime. Cities, 42, pp. 13-24, 2015.

[30] Pivo, G. \& Fisher, J.D., The walkability premium in commercial real estate investments. Real Estate Economics, 39, pp. 185-219, 2011.

[31] Matthews, J.W. \& Turnbull, G.K., Neighborhood street layout and property value: The interaction of accessibility and land use mix. J. Real Estate Finan. Econ., 35, pp. 111$141,2007$.

[32] Stavební slovník, Construction dictionary. www. stavebnikomunita.cz/page/stavebnislovnik-d. Accessed on: 20 Jul. 2020.

[33] WHO/Europe, BMI. www.euro.who.int/en/health-topics/disease-prevention/nutrition/ a-healthy-lifestyle/body-mass-index-bmi. Accessed on: 20 Jul. 2020.

[34] Feng, J., Glass, T.A., Curriero, F.C., Stewart, W.F. \& Schwartz, B.S., The built environment and obesity: A systematic review of the epidemiologic evidence. Health and Place, 16, pp. 175-190, 2010.

[35] Carlson, J.A. et al., Walking mediates associations between neighborhood activity supportiveness and BMI in the Women's Health Initiative San Diego cohort. Health and Place, 38, pp. 48-53, 2016.

[36] Guessous, I., Joost, S., Jeannot, E., Theler, J.-M., Mahler, P. \& Gaspoz, J.-M., A comparison of the spatial dependence of body mass index among adults and children in a Swiss general population. Nutrition and Diabetes, 4, 2014.

[37] James, P., Kioumourtzoglou, M.-A., Hart, J.E., Banay, R.F., Kloog, I. \& Laden, F., Interrelationships between walkability, air pollution, greenness, and body mass index. Epidemiology, 28, pp. 780-788, 2017.

[38] Gehl, J. \& Svarre, B., How to Study Public Life, Island Press: Washington DC, pp. 46$48,2013$.

[39] Nakládalová, M., Sovová, E., Ivanová, K., Kaletová, M., Lukl, J. \& Fialová, J., Risk factors for cardiovascular diseases in physicians. Biomed. Pap. Med., 149(2), pp. 293295, 2005.

[40] Sobková, L.F. \& Čertický, M., Urban mobility and influence factors: A case study of Prague. WIT Transactions on the Built Environment, vol. 176, WIT Press: Southampton and Boston, pp. 207-217, 2017.

[41] Auto*mat, Cyklistika v kopcovitých městech? Rozhodně ano! https://auto-mat.cz/ 23959/cyklistika-v-kopcovitych-mestech-rozhodne-ano. Accessed on: 9 Jul. 2020.

[42] Xing, Y., Volker, J. \& Handy, S., Why do people like bicycling? Modeling affect toward bicycling. Transportation Research Part F Traffic Psychology and Behaviour, 56, pp. 22-32, 2018.

[43] Wang, Y., Ao, Y., Zhang, Y., Liu, Y., Zhao, L. \& Chen, Y., Impact of the built environment and bicycling psychological factors on the acceptable bicycling distance of rural residents. Sustainability, 11(4404), 2019.

[44] Shashank, A. \& Schuurman, N., Unpacking walkability indices and their inherent assumptions. Health and Place, 55, pp. 145-154, 2019.

[45] The University of British Columbia, Walkability index. https://health-design.spph.ubc.ca/tools/walkability-index/. Accessed on: 20 Jul. 2020. 
[46] Soni, N. \& Soni, N., Benefits of pedestrianization and warrants to pedestrianize an area. Land Use Policy, 57, pp. 139-150, 2016.

[47] Disman, M., Jak se vyrábí sociologická znalost, Karolinum, 2002. 